\title{
Successful glycemic control using a flash glucose monitoring system for a pregnant woman with diabetes: a case report
}

\author{
Miyako Kishimoto ${ }^{1,2^{*}}$, Saori Tamada ${ }^{3}$ and Yoko Oshiba ${ }^{1,3}$
}

\begin{abstract}
Background: Glucose control for pregnant women with glucose intolerance is important, as hyperglycemia may adversely affect the mother and the fetus.

Case presentation: We report the case of a pregnant Japanese woman who experienced gestational diabetes mellitus during her first pregnancy and developed impaired glucose tolerance after the delivery. During her second pregnancy with twins, she required up to 75 units of injected insulin to control her postprandial hyperglycemia and occasionally experienced hypoglycemia. We used a newly developed flash glucose monitoring system, which allowed her to successfully achieve ideal glycemic control and experience an uncomplicated delivery.
\end{abstract}

Conclusion: We suggest that this flash glucose monitoring system may be clinically effective for similar cases that involve pregnant women with abnormal glucose tolerance.

Keywords: Gestational diabetes mellitus, Impaired glucose tolerance, Flash glucose monitoring system, Insulin

\section{Background}

Gestational diabetes mellitus (GDM) is glucose intolerance during pregnancy, and is associated with both maternal and fetal risks [1-5]. Women with GDM have an increased risk of developing impaired glucose tolerance (IGT) or type 2 diabetes [6-8]. We recently encountered a pregnant Japanese woman who was diagnosed with GDM during her first pregnancy and subsequently developed IGT after the delivery. During her second pregnancy, she required large doses of injected insulin and faced the possibility of premature labor. However, intensive care from an interdisciplinary healthcare team allowed her to achieve a successful delivery without serious adverse outcomes.

Appropriate glycemic control in this case was achieved using a novel sensor-based flash glucose monitoring (FGM) system (FreeStyle Libre ${ }^{\mathrm{mw}}$; Abbott Diabetes Care, Alameda, CA) that does not require routine finger pricks, which eliminates pain and inconvenience from the testing

\footnotetext{
* Correspondence: mkishimoto@iuhw.ac.jp

${ }^{1}$ Clinical Research Center, Department of Medicine, International University of Health and Welfare, Tokyo, Japan

${ }^{2}$ Department of Internal Medicine, Sanno Hospital, 8-10-16 Akasaka Minato,

Tokyo 107-0052, Japan

Full list of author information is available at the end of the article
}

process [9]. Data regarding the measured interstitial glucose levels are transferred to a display, which also shows a glucose trend arrow and a graph of the glucose readings from the previous $8 \mathrm{~h}$. These data can be uploaded and printed by using FreeStyle Libre software. Compared to conventional self-monitoring of blood glucose (SMBG) using capillary strips, the FGM system reduces the incidence of hypoglycemia among patients with type 1 diabetes, without a deterioration in their glycated hemoglobin (HbA1c) levels [10]. The FGM system can also be used as part of intensive insulin therapy for type 2 diabetes, which reduces the incidence of hypoglycemia without altering the patient's HbA1c levels [11]. According to the manufacturer's instruction, sensor glucose readings may not be accurate, and a finger prick test using a glucometer is required when 1) glucose levels change rapidly, as interstitial fluid glucose levels may not accurately reflect blood glucose levels, 2) the displayed value is not in accordance with the symptoms, and 3) hypoglycemia needs to be confirmed [12-14].

Therefore, the FGM system cannot be used as an alternative to conventional SMBG. However, this novel system appears to be a safe and effective adjunctive tool and our findings highlight its utility during the treatment of pregnant women with glucose intolerance. 


\section{Case presentation}

A 30-year-old pregnant Japanese woman was diagnosed with GDM at 23 weeks and 3 days of gestation during her first pregnancy, based on the results of a 75-g oral glucose tolerance test (OGTT). Her blood glucose levels before the test, after $60 \mathrm{~min}$, and after $120 \mathrm{~min}$ were $81 \mathrm{mg} / \mathrm{dL}, 151 \mathrm{mg} / \mathrm{dL}$, and $180 \mathrm{mg} / \mathrm{dL}$, respectively. She was not obese before the pregnancy, had a height of $163 \mathrm{~cm}$, a body weight of $54 \mathrm{~kg}$, a body mass index (BMI) of $20.3 \mathrm{~kg} / \mathrm{m}^{2}$ and had no family history of diabetes. She received dietary counselling, began SMBG (ONETOUCH UltraVue $^{\text {mu }}$ Johnson \& Johnson, New Brunswick, NJ), and successfully achieved good glycemic control until the day of her delivery (a healthy boy with a birth weight of $3164 \mathrm{~g})$. At 3 months after the delivery, she completed a follow-up 75-g OGTT, and the blood glucose levels before the test, after $30 \mathrm{~min}$, after $60 \mathrm{~min}$, and after $120 \mathrm{~min}$ were $82 \mathrm{mg} / \mathrm{dL}, 146 \mathrm{mg} / \mathrm{dL}, 102 \mathrm{mg} / \mathrm{dL}$, and $189 \mathrm{mg} / \mathrm{dL}$, respectively. Her plasma insulin levels before the test and after $30 \mathrm{~min}$ were $2.20 \mu \mathrm{U} / \mathrm{mL}$ and $33.2 \mu \mathrm{U} / \mathrm{ml}$, respectively. Therefore, she was diagnosed with IGT based on these results, an insulinogenic index of 0.48 , and a homeostatic model assessment of insulin resistance (HOMA-IR) result of 0.44. Thereafter, her HbA1c level was regularly monitored and ranged from $5.4 \%$ to $5.7 \%$.

At the age of 33 years, the patient became pregnant with twins. At approximately 5 weeks of gestation, her SMBG began showing high postprandial glucose levels (up to $140-180 \mathrm{mg} / \mathrm{dL}$ ), and she began self-administered insulin injections using insulin aspart (Novo Nordisk) three times per day before each meal. The doses of these insulin injections increased with gestational age, and reached 20-22 units before each meal. At 31 weeks and 3 days of gestation, the patient was urgently admitted to our hospital due to premature labor contractions. We initiated a continuous intravenous infusion $(500 \mathrm{~mL} /$ day of $5 \%$ glucose solution containing $50 \mathrm{mg}$ of ritodrine) that was continued until the day of her delivery. The patient experienced adverse effects from the ritodrine, required complete bed rest, and her glucose levels kept increasing $(2200 \mathrm{kcal} /$ day in 3 meals). Even with 25 units of injected insulin before each meal, her postprandial glucose levels increased to $211 \mathrm{mg} / \mathrm{dL}$ at $2 \mathrm{~h}$ after lunch, and she occasionally experienced hypoglycemia $(59 \mathrm{mg} / \mathrm{dL}$ at $3 \mathrm{~h}$ after lunch or $50 \mathrm{mg} / \mathrm{dL}$ at approximately $10 \mathrm{PM}$ ). Thus, to reduce the fluctuations in her glucose levels, her food intake $(2200 \mathrm{kcal} /$ day with $59 \%$ carbohydrates, $15 \%$ protein, and $26 \%$ fat) was separated into 5 meals: first breakfast at $8 \mathrm{AM}$, second breakfast at $10 \mathrm{AM}$, first lunch at noon, second lunch at $3 \mathrm{PM}$, and dinner at $6 \mathrm{PM}$. The patient also received 1 cup of yoghurt immediately before going to sleep (Fig. 1a). However, the patient subsequently experienced abdominal distension and difficulty eating, and we reduced her intake to $1960 \mathrm{kcal} /$ day (Fig. 1b).
Based on the increased meal frequency, the patient required more frequent SMBG and insulin injections, which she found to be painful and depressing. Thus, we introduced the FGM system, which does not require finger punctures, to reduce her physical and emotional burden. During the first few days after its introduction, the FGM system exhibited discrepancies with the results from the conventional SMBG method, especially when her glucose levels were $<70 \mathrm{mg} / \mathrm{dL}$ or $>180 \mathrm{mg} / \mathrm{dL}$. Therefore, she measured her glucose levels using both methods when her glucose levels were abnormally high or low. The patient also experienced difficulty consuming the second breakfast because of the short interval between the first and second breakfasts. Thus, her intake was revised to $1960 \mathrm{kcal} /$ day (53\% carbohydrates, $21 \%$ protein, and $26 \%$ fat) in 4 meals: breakfast at $8 \mathrm{AM}$, first lunch at noon, second lunch at $3 \mathrm{PM}$, and dinner at $6 \mathrm{PM}$. The re-distributed meals and flash glucose monitoring system allowed the patient to achieve good glycemic control, and the doses of the injected insulin decreased to 35 units (Fig. 1c) and then to 18 units (Fig. 1d). Her HbA1c level was maintained, ranging from $5.1 \%$ to $5.2 \%$ (these values were considered as a reference due to her anemia), and her glycoalbumin levels ranged from $10.6 \%$ to $11.6 \%$ during pregnancy. She gained $10.5 \mathrm{~kg}$ during her pregnancy and subsequently delivered twins via Caesarean procedure (2280 g and $2778 \mathrm{~g})$ at 37 weeks and 1 day of gestation, without any adverse events or hypoglycemia. After the delivery, the patient stopped all insulin injections and had glucose levels of $70-140 \mathrm{mg} / \mathrm{dL}$ throughout the day with a normal puerperium diet $(2200 \mathrm{kcal} /$ day in 3 meals) (Fig. 1e). The patient and her twins were discharged in healthy states at 7 days after the delivery.

\section{Discussion}

Recently, results of studies on the use of the FGM system in terms of accuracy and patient's satisfaction were favorable $[10,11,13-16]$, and the availability of the FGM system as an alternative to glucose monitoring can be positively evaluated [13]. However, this system has certain precautions and disadvantages, including the mismatch between sensor glucose reading and SMBG due to the time lag of glucose from the intravascular to interstitial compartment $[17,18]$, and this effect is particularly pronounced when glucose levels are rapidly increasing or decreasing [14]. In addition, the use of glucose sensor is less accurate during hypoglycemia [16]. As for the precautions and limitations stated in the manufacturer's manual, the FGM system should not be used by pregnant women or individuals on dialysis because the system has not been evaluated in these populations [12]. During pregnancy, changes in the water content in the body compartments may affect the accuracy of glucose measurements when the FGM system is used. Therefore, the evaluation of the patient's sensor reading 


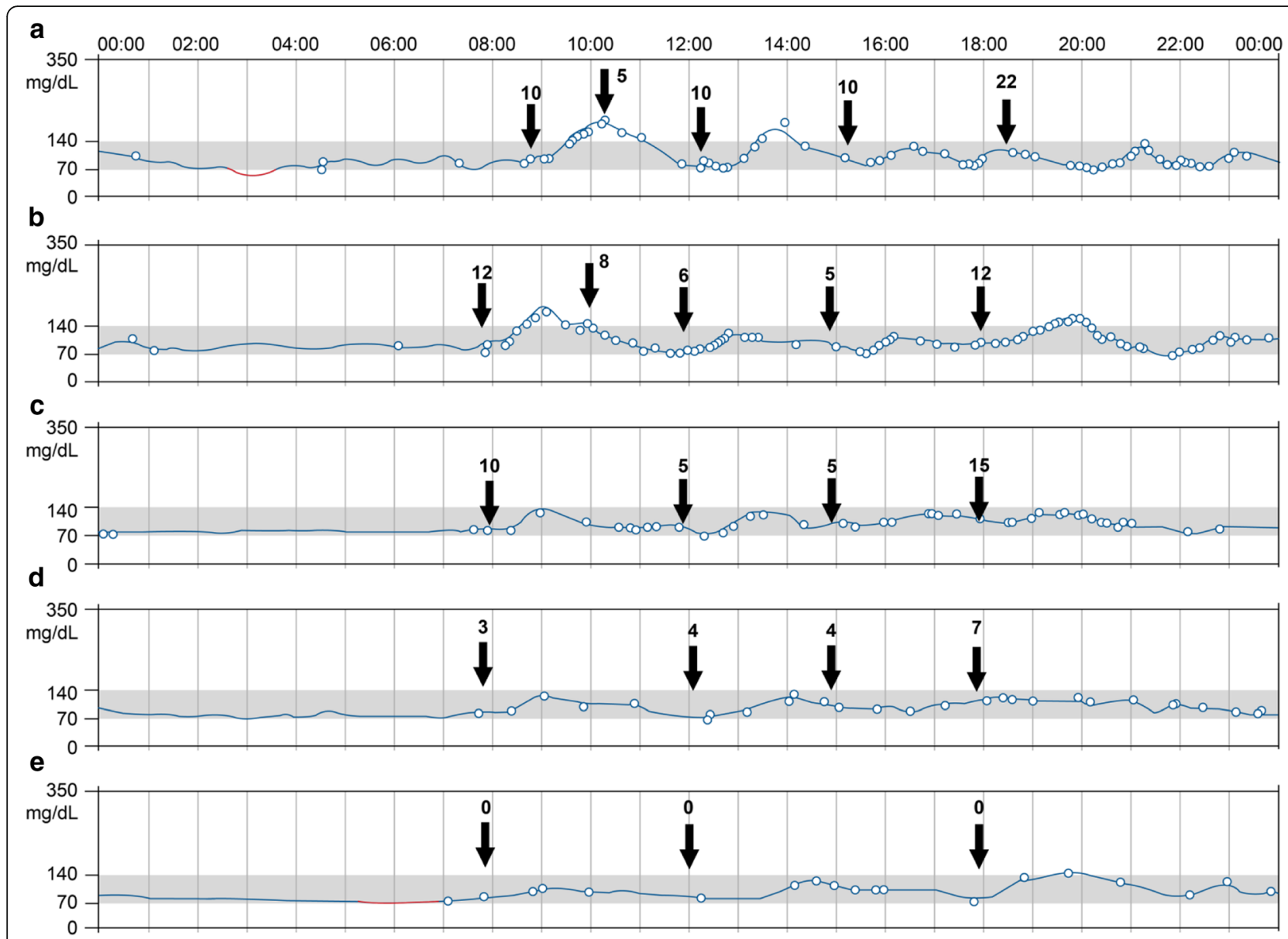

Fig. 1 The results of continuous glucose monitoring using the sensor-based flash glucose monitoring system. The arrows indicate the timing of the patient's meals and insulin injections. The numbers above the arrows indicate the numbers of the units for each insulin injection. The patient needed 57 units of injected insulin on day 8 (2200 kcal in 5 meals) (a), 43 units of injected insulin on day 10 (1960 kcal in 5 meals) (b), 35 units of injected insulin on day 17 (1960 kcal in 4 meals) (c), 18 units injected insulin on day 38 (1960 kcal in 4 meals) (d), and no injected insulin at 3 days after the delivery (2200 kcal in 3 meals) (e)

required special precation, and a simultaneous SMBG must also be performed. Thus, the patient used the FGM system and conventional SMBG for the first week, and we monitored the differences between the two results. We observed several discrepancies during periods of hypoglycemia (e.g., conventional SMBG: $86 \mathrm{mg} / \mathrm{dL}$, the FGM system: $68 \mathrm{mg} / \mathrm{dL}$ ) and hyperglycemia (conventional SMBG: $218 \mathrm{mg} / \mathrm{dL}$, the FGM system: $182 \mathrm{mg} / \mathrm{dL}$ ). However, the two results were frequently similar, and any differences were within the allowable range. Therefore, the patient mainly used the FGM system and only occasionally used conventional SMBG from the second week after the introduction of the FGM system to the day of her discharge.

Blood glucose monitoring at 4-7 times per day can help improve perinatal and pregnancy outcomes [19-21], and our patient originally measured her glucose levels four times per day (before breakfast and after each meal), based on the recommendations for patients with GDM and preexisting diabetes [3]. However, after her diet was changed to 4-5 meals, she had to perform conventional SMBG at least 8 times per day, based on the recommendations of the American College of Obstetricians and Gynecologists [22] and the American Diabetes Association. For women with type 1 or type 2 diabetes and GDM, these recommendations target fasting glucose levels of $\leq 95 \mathrm{mg} / \mathrm{dL}$ $(5.3 \mathrm{mmol} / \mathrm{L})$ and either 1 -h postprandial glucose levels of $\leq 140 \mathrm{mg} / \mathrm{dL}(7.8 \mathrm{mmol} / \mathrm{L})$ or 2 -h postprandial glucose levels of $\leq 120 \mathrm{mg} / \mathrm{dL}(6.7 \mathrm{mmol} / \mathrm{L})$ [3]. Thus, she would have required more frequent SMBG to adjust her insulin injections, and the increased frequency of these tests caused her to become stressed and depressed.

The FGM system does not require painful finger pricks, and patients are willing to perform 3 times more frequent glucose monitoring compared to conventional SMBG [10]. After introducing this novel system, our patient completed more frequent glucose monitoring, and the improved blood glucose monitoring allowed her to select more appropriate injected insulin doses. This improved accuracy 
resulted in a decrease in her daily dosage from 75 units to 18 units. Furthermore, the patient was able to detect and manage early-stage hypoglycemia before it progressed any further.

Even before the introduction of ritodrine at her hospitalization, the patient required up to 66 units of injected insulin per day (20-22 units before each meal). Information regarding the effects of hyperglycemia during twin pregnancies is sparse, and it remains unclear whether twin pregnancies are associated with increased risks of maternal, fetal, and neonatal complications, compared to singleton pregnancies [23-29]. Nevertheless, we suggest that the large required doses of injected insulin can be partially explained by her twin pregnancy.

\section{Conclusion}

In conclusion, we suggest that the FGM system is safe and effective for glycemic management of pregnant women with abnormal glucose tolerance, and especially for women who require frequent SMBG because of their frequent meals and insulin injections. This new system could be a less invasive alternative for patients who need careful and frequent glucose monitoring and could be a beneficial system for people who care for these patients. A large study of pregnant women with glucose intolerance is needed to identify patients who will experience the greatest benefits from this novel monitoring system.

\section{Abbreviations}

FGM: Flash glucose monitoring; GDM: Gestational diabetes mellitus; IGT: Impaired glucose tolerance; OGTT: Oral glucose tolerance test; SMBG: Self-monitoring of blood glucose

\section{Acknowledgements}

The authors thank Mr. Ryutaro Kato for his helpful suggestions regarding diet therapy for our patient.

\section{Funding}

The authors received no financial support for the study, authorship and/or publication of this article.

\section{Availability of data and materials}

Please contact author for data requests.

\section{Authors' contributions}

MK was involved in data collection and drafted the manuscript. ST and YO conceived the study and critically revised the final manuscript. All authors approved of the final manuscript for publication.

\section{Ethics approval and consent to participate}

All procedures followed were in accordance with the ethical standards of the responsible committee on human experimentation (institutional and national) and with the Helsinki Declaration of 1975, as revised in 2000 and 2008. A written informed consent was obtained from the patient prior to the use of the FGM system. This case report was approved by the Ethics Committee of the Sanno Hospital.

\section{Consent for publication}

We obtained written informed consent from the patient for publication.

\section{Competing interests}

The authors declare that they have no competing interests.

\section{Publisher's Note}

Springer Nature remains neutral with regard to jurisdictional claims in published maps and institutional affiliations.

\section{Author details}

${ }^{1}$ Clinical Research Center, Department of Medicine, International University of Health and Welfare, Tokyo, Japan. ${ }^{2}$ Department of Internal Medicine, Sanno Hospital, 8-10-16 Akasaka Minato, Tokyo 107-0052, Japan. ${ }^{3}$ Department of Obstetrics and Gynecology, Sanno Hospital, 8-10-16 Akasaka Minato, Tokyo 107-0052, Japan.

Received: 21 May 2017 Accepted: 31 October 2017

Published online: 06 November 2017

\section{References}

1. Chen P, Wang S, Ji J, et al. Risk factors and management of gestational diabetes. Cell Biochem Biophys. 2015;71:689-94.

2. HAPO Study Cooperative Research Group, Metzger BE, Lowe LP, Dyer AR, et al. Hyperglycemia and adverse pregnancy outcomes. N Engl J Med. 2008; 358:1991-2002

3. American Diabetes Association. Management of diabetes in pregnancy. Sec. 13. In standards of medical Care in Diabetes-2017. Diabetes Care. 2017; 40(Suppl.1):S114-9.

4. Holmes VA, Young IS, Patterson CC, et al. Diabetes and Pre-eclampsia Intervention Trial Study Group. Optimal glycemic control, pre-eclampsia, and gestational hypertension in women with type 1 diabetes in the diabetes and pre-eclampsia intervention trial. Diabetes Care. 2011;34:1683-8.

5. Dabelea $D$, Hanson RL, Lindsay RS, et al. Intrauterine exposure to diabetes conveys risks for type 2 diabetes and obesity: a study of discordant sibships. Diabetes. 2000;49:2208-11.

6. Kim C, Newton KM, Knopp RH. Gestational diabetes and the incidence of type 2 diabetes: a systematic review. Diabetes Care. 2002;25:1862-8.

7. O'Sullivan JB. Diabetes mellitus after GDM. Diabetes. 1991;40(Suppl 2):131-5.

8. Bellamy L, Casas JP, Hingorani AD, et al. Type 2 diabetes mellitus after gestational diabetes: a systematic review and meta-analysis. Lancet. 2009;373:1773-9.

9. FreeStyle Libre Flash Glucose Monitoring System. https:/www.freestylelibre.us/ Accessed 3 Nov 2017.

10. Bolinder J, Antuna R, Geelhoed-Duijvestijn P, et al. Novel glucose-sensing technology and hypoglycaemia in type 1 diabetes: a multicentre, nonmasked, randomised controlled trial. Lancet. 2016;388:2254-63.

11. Haak T, Hanaire $H$, Ajjan R, et al. Flash glucose-sensing technology as a replacement for blood glucose monitoring for the Management of InsulinTreated Type 2 diabetes: a multicenter, open-label randomized controlled trial. Diabetes Ther. 2017:8:55-73.

12. FreeStyle Libre Indications and Important Safety Information. https://www. myfreestyle.com/provider/. Accessed 3 Nov 2017.

13. Heinemann L, Freckmann G. CGM versus FGM; or, continuous glucose monitoring is not flash glucose monitoring. J Diabetes Sci Technol. 2015;9:947-50.

14. Hoss U, Budiman ES, Liu H, et al. Feasibility of factory calibration for subcutaneous glucose sensors in subjects with diabetes. J Diabetes Sci Technol. 2014;8:89-94.

15. Bailey T, Bode BW, Christiansen MP, et al. The performance and usability of a factory-calibrated flash glucose monitoring system. Diabetes Technol Ther. 2015:17:787-94.

16. Aberer F, Hajnsek M, Rumpler M, et al. Evaluation of subcutaneous glucose monitoring systems under routine environmental conditions in patients with type 1 diabetes. Diabetes Obes Metab. 2017;19:1051-5.

17. Basu A, Dube S, Slama M, et al. Time lag of glucose from intravascular to interstitial compartment in humans. Diabetes. 2013;62:4083-7.

18. Basu A, Dube $S$, Veettil $S$, et al. Time lag of glucose from intravascular to interstitial compartment in type 1 diabetes. J Diabetes Sci Technol. 2015;9:63-8.

19. Reader D, Splett P, Gunderson EP, Diabetes Care and Education Dietetic Practice Group. Impact of gestational diabetes mellitus nutrition practice guidelines implemented by registered dietitians on pregnancy outcomes. J Am Diet Assoc. 2006;106:1426-33.

20. Crowther CA, Hiller JE, Moss JR, et al. Australian Carbohydrate Intolerance Study in Pregnant Women (ACHOIS) Trial Group. Effect of treatment of gestational diabetes mellitus on pregnancy outcomes. N Engl J Med. 2005;352:2477-86.

21. Langer $\mathrm{O}$, Rodriguez $\mathrm{DA}$, Xenakis EM, et al. Intensified versus conventional management of gestational diabetes. Am J Obstet Gynecol. 1994;170:1036-47. 
22. Committee on Practice Bulletins-Obstetrics. Practice bulletin no. 137: gestational diabetes mellitus. Obstet Gynecol. 2013;122:406-16.

23. American College of Obstetricians and Gynecologists Committee on Practice Bulletins-Obstetrics, Society for Maternal-Fetal Medicine, ACOG Joint Editorial Committee. ACOG practice bulletin \#56: multiple gestation: complicated twin, triplet, and high-order multifetal pregnancy. Obstet Gynecol. 2004;104:869-83.

24. Schwartz DB, Daoud Y, Zazula P, et al. Gestational diabetes mellitus: metabolic and blood glucose parameters in singleton versus twin pregnancies. Am J Obstet Gynecol. 1999;181:912-4.

25. Lai FY, Johnson JA, Dover D, et al. Outcomes of singleton and twin pregnancies complicated by pre-existing diabetes and gestational diabetes: a population-based study in Alberta, Canada, 2005-11. J Diabetes. 2016;8:45-55.

26. Buhling KJ, Henrich W, Starr E, et al. Risk for gestational diabetes and hypertension for women with twin pregnancy compared to singleton pregnancy. Arch Gynecol Obstet. 2003;269:33-6.

27. Lucovnik M, Blickstein I, Verdenik I, et al. Impact of pre-gravid body mass index and body mass index change on preeclampsia and gestational diabetes in singleton and twin pregnancies. J Matern Fetal Neonatal Med. 2014;27:1901-4

28. Morikawa M, Yamada T, Akaishi R, et al. Prevalence of hyperglycaemia in singleton versus twin pregnancy. Diabetes Metab Res Rev. 2015;31:198-203.

29. Poulain C, Duhamel A, Garabedian C, et al. Outcome of twin pregnancies associated with glucose intolerance. Diabetes Metab. 2015:41:387-92.

\section{Submit your next manuscript to BioMed Central} and we will help you at every step:

- We accept pre-submission inquiries

- Our selector tool helps you to find the most relevant journal

- We provide round the clock customer support

- Convenient online submission

- Thorough peer review

- Inclusion in PubMed and all major indexing services

- Maximum visibility for your research

Submit your manuscript at www.biomedcentral.com/submit 